\title{
A Meta-Analysis of the Impact of Monensin in Lactating Dairy Cattle. Part 1. Metabolic Effects
}

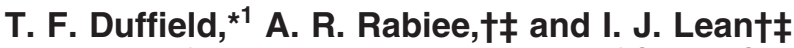 \\ *Department of Population Medicine, University of Guelph, Guelph, Ontario, N1G 2W1 Canada \\ †Strategic Bovine Services, PO 660, Camden, New South Wales, Australia \\ łUniversity of Sydney, Camden, New South Wales, Australia
}

\section{ABSTRACT}

A meta-analysis of the impact of monensin on metabolism of dairy cattle was conducted following a search of the literature. A total of 59 studies with monensin feeding in dairy cattle were identified in which $30 \mathrm{pa}-$ pers and 45 trials contained metabolic data. The $\beta$ hydroxybutyrate (BHBA) data were obtained from over 4,000 cows and 115 trial sites. Data for each trial were extracted and analyzed using meta-analysis software in Stata. Estimated effect sizes of monensin were calculated on blood concentrations of BHBA, acetoacetate, nonesterified fatty acids (NEFA), glucose, cholesterol, urea, calcium, insulin, and milk urea. Monensin use in lactating dairy cattle significantly reduced blood concentrations of BHBA $13 \%$, acetoacetate $14 \%$, and NEFA $7 \%$. Monensin increased glucose $3 \%$ and urea 6\%. Monensin had no significant effect on cholesterol, calcium, milk urea, or insulin. Heterogeneity was significant for BHBA and cholesterol [ $\mathrm{I}^{2}$ (measure of variation beyond chance) $=37$ and $54 \%$, respectively]; therefore, random effects models were used for those analytes. Publication bias existed with the monensin effect on BHBA, with a tendency for studies to be published if there was a significant reduction in this ketone. Meta-regression analysis of the effect sizes obtained from the metabolic data showed that method of delivery, timing of administration, stage of lactation, and diet were influential in modifying effect size of monensin treatment. Use of top dress or delivery via a controlled release capsule reduced the magnitude of effect on BHBA (coefficient +0.353 ); however, top dress use compared with controlled release capsule or total mixed ration enhanced the monensin effect on glucose (coefficient +0.296) There was a greater impact with monensin on reducing BHBA in early lactation (coefficient -0.151) and in pasture-based trials (coefficient -0.194). Use of monensin in both the pre- and postcalving periods was associated

Received August 12, 2007.

Accepted November 28, 2007.

${ }^{1}$ Corresponding author: tduffiel@uoguelph.ca with an enhanced impact on NEFA (coefficient -0.254). Monensin had less impact on serum glucose in the precalving time period (coefficient -0.237 ). These findings demonstrate an improvement in the energy metabolism of dairy cows supplemented with monensin.

Key words: monensin, dairy cattle, meta-analysis, metabolic

\section{INTRODUCTION}

Monensin is a carboxylic polyether ionophore produced by a naturally occurring strain of Streptomyces cinnamonensis (Haney and Hoehn, 1967) and is provided to cattle orally as a sodium salt. Ionophores interfere with ion transport across cell membranes, thereby creating energy loss in bacterial cells, resulting in bacterial death. Monensin selectively inhibits gram-positive bacteria rather than gram-negative bacteria because of differences in bacterial cell-wall structure. The result of this shift in rumen bacterial populations has several impacts on ruminant metabolism. These include increased efficiency of energy metabolism, improved nitrogen metabolism, and effects on digestion, including reductions in both bloat and lactic acidosis (Schelling, 1984). Monensin changes the ratio of VFA in the rumen, increasing propionic acid production and reducing the molar percentages of butyric and acetic. Increased production of propionic acid from the rumen increases hepatic gluconeogenic flux.

Since the late 1980s many papers were published on the effects of monensin in lactating dairy cattle. Recently, approvals for use of monensin in lactating cows were obtained in Canada and the United States, whereas the product has been available for dairy cattle in other countries such as Mexico, Australia, and New Zealand for many years. The reported impacts of monensin on energy metabolism, including effects on serum ketones, NEFA, glucose, and urea, were not always consistent. Meta-analysis is a useful tool that can be used to both summarize effects of treatment across studies and to investigate factors explaining potential heterogeneity of response. It is a technique that was 
used to summarize research findings and treatment effects in human health care for several years (Egger et al., 2001). Many examples of the power and utility of meta-analysis exist in the veterinary and animal science literature. Recent examples include a metaanalysis of dietary predictors of milk fever (Lean et al., 2006) and the impact of bovine somatotropin on production and health (Dohoo et al., 2003a).

Given the large body of literature on monensin use in dairy cattle and recent approvals in the United States and Canada for lactating dairy cattle, it was concluded that an investigation of monensin by meta-analysis would be helpful in describing its impact and in explaining differences in responses between studies. The purpose was to describe the effect of monensin on metabolic traits in lactating dairy cattle using meta-analytic methods.

\section{MATERIALS AND METHODS}

A literature search and screening process was initially conducted using PubMed, Agricola, CAB, and Google Scholar search engines to create a data set of monensin papers using the key words "monensin and cattle" or "monensin and cow." Authors of research on monensin were contacted to obtain trial reports and unpublished or published information not identified by other search methods. Two of the authors had knowledge of studies completed but not yet published, and these papers were solicited for evaluation. In addition, Elanco Animal Health (Guelph, Ontario, Canada; Macquarie Park, New South Wales, Australia; Greenfield, IN) was asked for unpublished reports that might be used for this analysis. All trial reports and papers were initially screened for acceptability by determining if the research was conducted on dairy cows. After discarding papers that were not dairy research, a starting data set of 161 papers or reports was achieved.

\section{Selection for Inclusion and Exclusion Criteria}

For inclusion, papers must have been conducted on dairy cows. Thus, all review papers $(n=7)$, herd-level analysis $(n=4)$, and nontarget species papers such as research on beef, heifers, and calves $(n=46)$ were excluded. Five studies were discarded that contained solely outcome measures such as impact on the fecal shedding of Mycobacterium avium paratuberculosis (Hendrick et al., 2006) or the effect of monensin on neutrophil function (Stephenson et al., 1996) that were not repeated in the literature and thus could not be subjected to meta-analysis. The pharmacology or toxicity of monensin was not an outcome objective for these meta-analyses, and thus 6 of these papers were re- jected. An additional 9 papers were rejected because of data duplication. In this case, the peer-reviewed paper took precedence over an abstract or proceedings paper. Four papers involved an acidosis challenge that does not reflect a normal or typical feeding situation, and these papers were rejected. This data screening process left 80 papers to evaluate study quality for inclusion in the meta-analysis. Studies were required to be randomized trials (completely randomized, complete block, or factorial designs) to be eligible for analysis, but not necessarily blinded. Trials with cross-over and Latin square designs were excluded, due to small sample size, and potential problems with rumen adaptation periods. Trials with a direct comparison of monensin treatment to another treatment (positive control) but without a control group were excluded. There were 5 papers rejected because they were a Latin square or a crossover design. Other rejection reasons included lack of a control group $(n=6)$, lack of randomization $(n=2)$, and no reporting of measures of dispersion or $P$-values $(\mathrm{n}=$ 8). Efforts were made to contact all authors where measures of dispersion were missing for additional information so that the data could still be used, if possible. Finally, there were 59 papers of 80 eligible studies (74\%) that provided useable data and appropriate measures of variance on variable outcomes.

There were 30 papers available for evaluating the impact of monensin on metabolic indicators in lactating dairy cattle. A template for data extraction was drafted, which included number of cows per treatment group, mean, and standard error. If the standard error was not published, it was either estimated from the exact $P$-values or other measures of variance, or the data were excluded. In the case where a $P$-value was reported as less than a number (i.e., <0.05), the number was used as the $P$-value for the standard error calculation. Other factors that influenced the outcomes of interest were included in the data extraction process including DIM at treatment start, stage of lactation, treatment dose $(\mathrm{mg} / \mathrm{d})$, duration of treatment, method of delivery of monensin [in-feed, top dress, or controlled release capsule (CRC)], breed, feeding system (e.g., use of pasture), type of paper [peer-reviewed (yes/no)], and the use of one control group for multiple treatments. Data for all the analytes measured in each study were extracted and entered into a relational database. If possible, data were extracted both as one summary number and also stratified by time periods (Pre = before calving, Post 1 = first month after calving, Post $2=$ second month after calving, and Post $3=\geq 3$ mo postcalving). This strategy allowed exploration of possible differences in effect of treatment of different stages of lactation. Yet, for the initial meta-analysis of all metabolites, either the summary value of the outcome for that study or a 
single reported value for the study was used, resulting in one control and one treatment value per analyte per trial. Subsequent analysis using all the data stratified by time period (where possible) was conducted to allow exploration of stage of lactation effects and other potential influencers with meta-regression.

Outcomes used in this meta-analysis included the blood (blood, plasma, or serum) concentrations of BHBA, acetoacetate, NEFA, glucose, urea, insulin, cholesterol and calcium, and milk urea. For the remainder of this paper, serum or blood or plasma may be used interchangeably because the analysis considered all the measures together. A minimum of 6 trials worth of data for any outcome was arbitrarily set as the requirement for assessing impact of treatment.

\section{Statistical Analysis}

A meta-analysis was conducted on the extracted outcomes using Stata (Intercooled Stata V. 9.0, Stata Corp., College Station, TX). A fixed effect model was first conducted for each metabolite to estimate the effect size, $95 \%$ confidence intervals, and statistical significance of effect size. The effect size estimate analysis was conducted using a standardized $\mathrm{z}$ statistic, which allowed analysis that was independent of differences in unit measurement. Still, for all significant outcomes, unit of measurement was converted to the International System of Units (SI) values to allow the calculation of weighted mean differences of treatment relative to control. This included the conversion of all urea-N values in milligrams per deciliter to urea in millimoles per liter by multiplying the urea-N value by 0.357 .

Variation in experiment level effect size was assessed with a $\chi^{2}$ test for heterogeneity (Egger et al., 2001). An $\alpha$-level of 0.10 was used because of the relatively low power of the $\chi^{2}$ test to detect heterogeneity among the experiments. Heterogeneity of results among trials was quantified using the $I^{2}$ statistic (Higgins et al., 2003). The $I^{2}$ statistic describes the percentage of total variation across studies that is due to heterogeneity rather than chance. Where $Q$ is the $\chi^{2}$ heterogeneity statistic and $\mathrm{k}$ is the number of trials, $I^{2}$ was calculated as

$$
I^{2}=\frac{Q-(k-1)}{Q} \times 100 .
$$

Uncertainty intervals for $I^{2}$ (dependent on $Q$ and $k$ ) were calculated. Negative values of $I^{2}$ were put equal to zero; consequently, $I^{2}$ lay between 0 and $100 \%$. A value greater than $50 \%$ may be considered substantial heterogeneity.

If there was evidence of heterogeneity, a random effects model was used. A meta-regression analysis was subsequently used to explore the sources of heterogeneity of response, using the individual effect size for each trial as the outcome and the associated standard error of the effect size as the measure of variance. Metaregression was conducted by first screening individual variables such as dose, DIM at treatment start, delivery method, or diet type in a univariate regression with a liberal $P$-value cutoff of $P=0.20$. Variables such as dose and DIM at treatment start were treated as continuous variables. Other variables were coded as present or absent and were dichotomous. All variables meeting the first screening criteria were entered into a backward stepwise regression method until all variables that remained were significant at $P<0.05$. Forest plots were used to visually display the estimated effect size (ES), 95\% confidence intervals, and study weights. Publication bias was investigated both graphically with funnel plots and statistically using Begg's (Begg and Manumdar, 1994) and Egger's tests (Egger et al., 1997). In the case of significant publication bias, the number of studies needed to reverse the reported findings (FailSafe n) was calculated based on Rosenthal's methods (Rosenthal, 1979). Finally, the influence of individual studies was assessed with the use of an influence plot to determine the impact of removing individual studies on the effect size estimate (Dohoo et al., 2003b). Pearson correlations between NEFA, BHBA, glucose, and urea effect sizes were explored to measure the correlation in effect on these parameters.

\section{RESULTS}

A summary of the papers used for the various metaanalyses is provided in Table 1 . There were 30 papers containing 45 trials with monensin and metabolic outcomes. Some studies contained a summary of 1 trial conducted on multiple trial sites, whereas other studies reported multiple trials conducted at a single trial site. A summary of all meta-analysis findings for each metabolite is presented in Table 2. Over all the trials analyzed, monensin decreased blood concentrations of BHBA (ES $=-0.334, P=0.001)$, NEFA $(\mathrm{ES}=-0.143$, $P=0.006)$, and acetoacetate $(\mathrm{ES}=-0.312, P=0.003)$, and increased blood concentrations of glucose (ES = $0.154, P=0.0001)$ and urea $(\mathrm{ES}=0.154, P=0.0001)$. Monensin had no effect on serum cholesterol, calcium, and insulin or milk urea.

A forest plot for the impact of monensin on BHBA is presented in Figure 1. From the plot it is apparent that there is heterogeneity in the response of monensin from trial to trial on serum BHBA. The $\mathrm{Q} \chi^{2}$ statistic indicated that this heterogeneity was significant $\left(\chi^{2}=\right.$ 50.72 , df $=32 ; P=0.019$ ). Thus, the model for BHBA was evaluated using a random effect, and the possible 
Table 1. Summary of papers used for meta-analysis of metabolic effects of monensin in lactating dairy cows

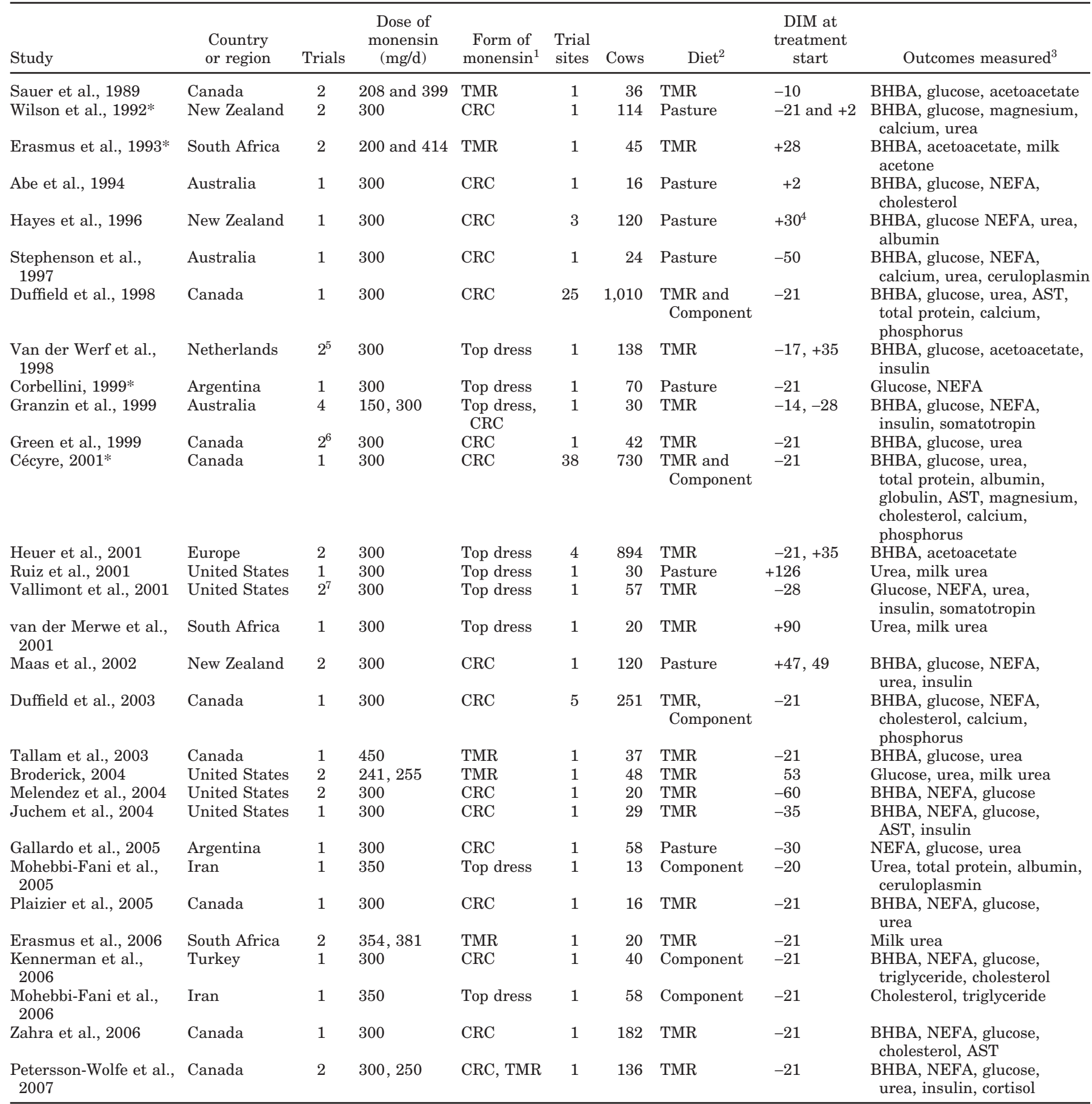

*Thesis, abstract, unpublished paper, trial report.

${ }^{1}$ Form of monensin: CRC = controlled release capsule, Top dress = dose of monensin fed to the cow included with a small amount of supplement, TMR = dose of monensin included in the TMR.

${ }^{2}$ Diet: Component $=$ forages fed separate from concentrate, Pasture = grazed forage comprised majority of diet.

${ }^{3} \mathrm{AST}=$ aspartate aminotransferase.

${ }^{4}$ Estimated DIM at treatment start.

${ }^{5}$ Data from one trial excluded because no measure of variance was recorded.

${ }^{6}$ Data used only from prefeed restriction period.

${ }^{7}$ Treatment stopped at calving; precalving data used only. 
Table 2. Summary of effect size estimates of monensin on plasma/serum/blood parameters in lactating dairy cows derived from metaanalysis

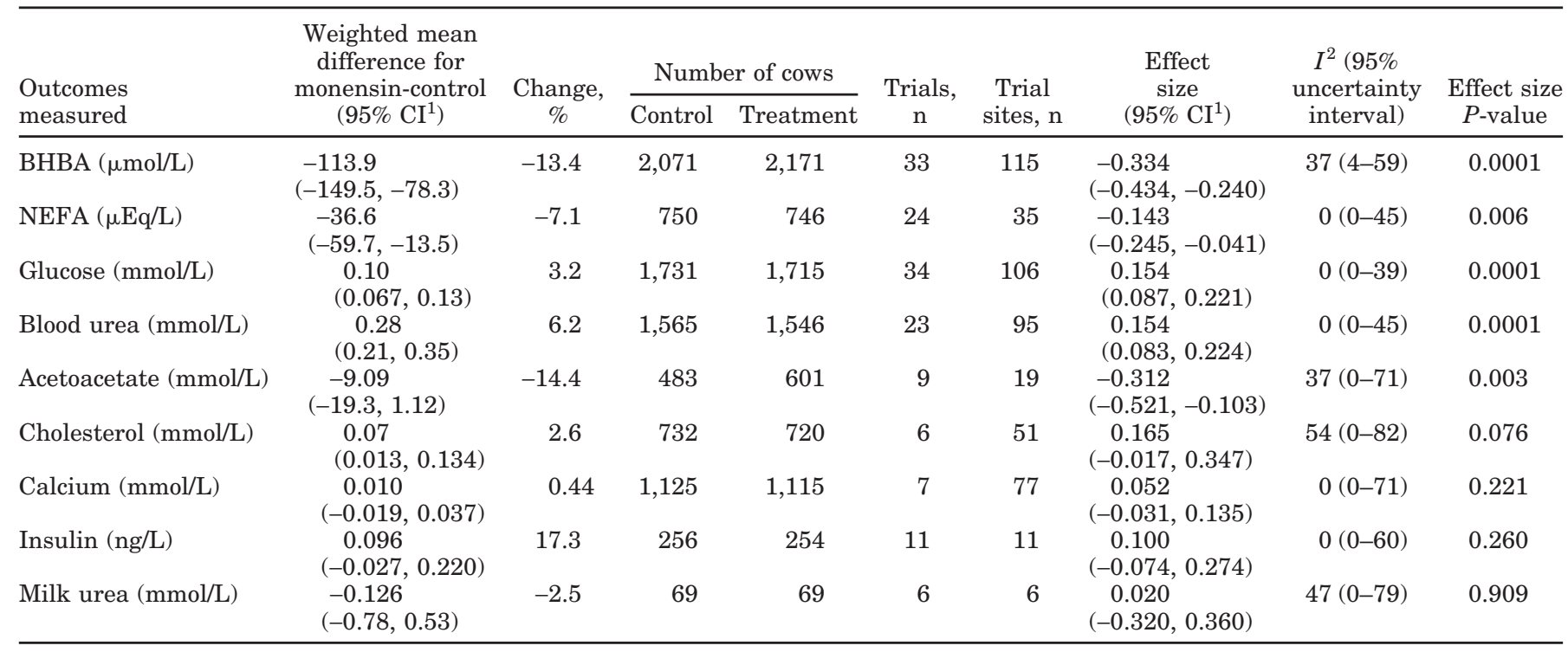

${ }^{1} \mathrm{CI}=$ confidence interval.

sources of heterogeneity were explored with meta-regression. Meta-analysis output from the data set that included stage of lactation produced very similar ES estimates (data not shown). Subsequent meta-regression analysis conducted to explore reasons for heterogeneity resulted in 3 significant variables that influenced the effect size for BHBA: 1) a consistent daily dose (CRC or top dress), 2) early lactation cows (within $30 \mathrm{~d}$ of calving), and 3) pasture feeding (Table 3). Effects of monensin on BHBA were more consistent, but less in effect with a consistent daily delivery (CRC or top dress) compared with inclusion in the TMR, and were greater in effect for pasture-based dairy cows and for cows in early lactation. The Begg's test for publication bias was significant for the BHBA analysis $(P=0.02)$, and the associated funnel plot (Figure 2) illustrates a bias toward smaller studies that reported responses when BHBA was lower with monensin treatment and a lack of small studies that may have found an increase in BHBA with monensin. Nevertheless, the estimated failsafe number (Rosenthal, 1979) indicated that it would require approximately 81 trials with opposite results to those available to reverse the findings that monensin treatment lowered BHBA concentrations in blood.

Forest plots for blood NEFA, glucose, and urea are illustrated in Figures 3, 4, and 5, respectively. Similar stage of lactation analysis and meta-regression was performed for each of these variables as was conducted for BHBA (Table 3). No variables were found to modify effect size estimates for monensin on urea. In all cases the effect size estimates obtained for the data including stage of lactation were similar to initial models.
The ES for glucose was significantly lower for samples obtained during the precalving time period compared with samples measured at any other stage of lactation (Table 3). Other variables influencing glucose included top dress delivery of treatment (compared with TMR or CRC delivery), dose of monensin in milligrams per day, and the use of a single control group for multiple treatments (compared with studies having 1 control and 1 treatment group). The only variable associated with the monensin ES for NEFA was inclusion of monensin in the pre- and the postcalving diet (compared with monensin inclusion in only the precalving or only the postcalving diet), which increased the effect of monensin in lowering blood NEFA concentrations. The stages of lactation or other factors did not influence the effect of monensin on urea. There was no publication bias identified for glucose, NEFA, or urea.

There was evidence of heterogeneity for cholesterol data $\left(\chi^{2}=10.87, \mathrm{df}=5, P=0.05\right)$; therefore, a random effects model was used for these variables. Nonetheless, no meta-regression analysis was attempted for cholesterol data because of small sample size.

The impact of influential studies on all models was tested using influence analysis. Although, there were influential studies, especially those with larger sample sizes, inclusion or removal of these studies did not change the direction of effect in any analysis and caused little change in the overall effect size estimates. An example of influence analysis is presented in Figure 6 for BHBA. The studies with the greatest positive and negative influence were Sauer et al. (1989) and Duffield et al. (1998). Removal of one of the trials (highest dose) 


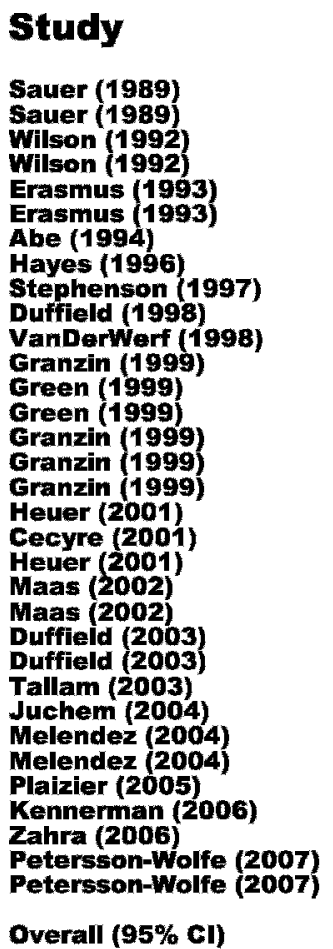

Overall (95\% CI)

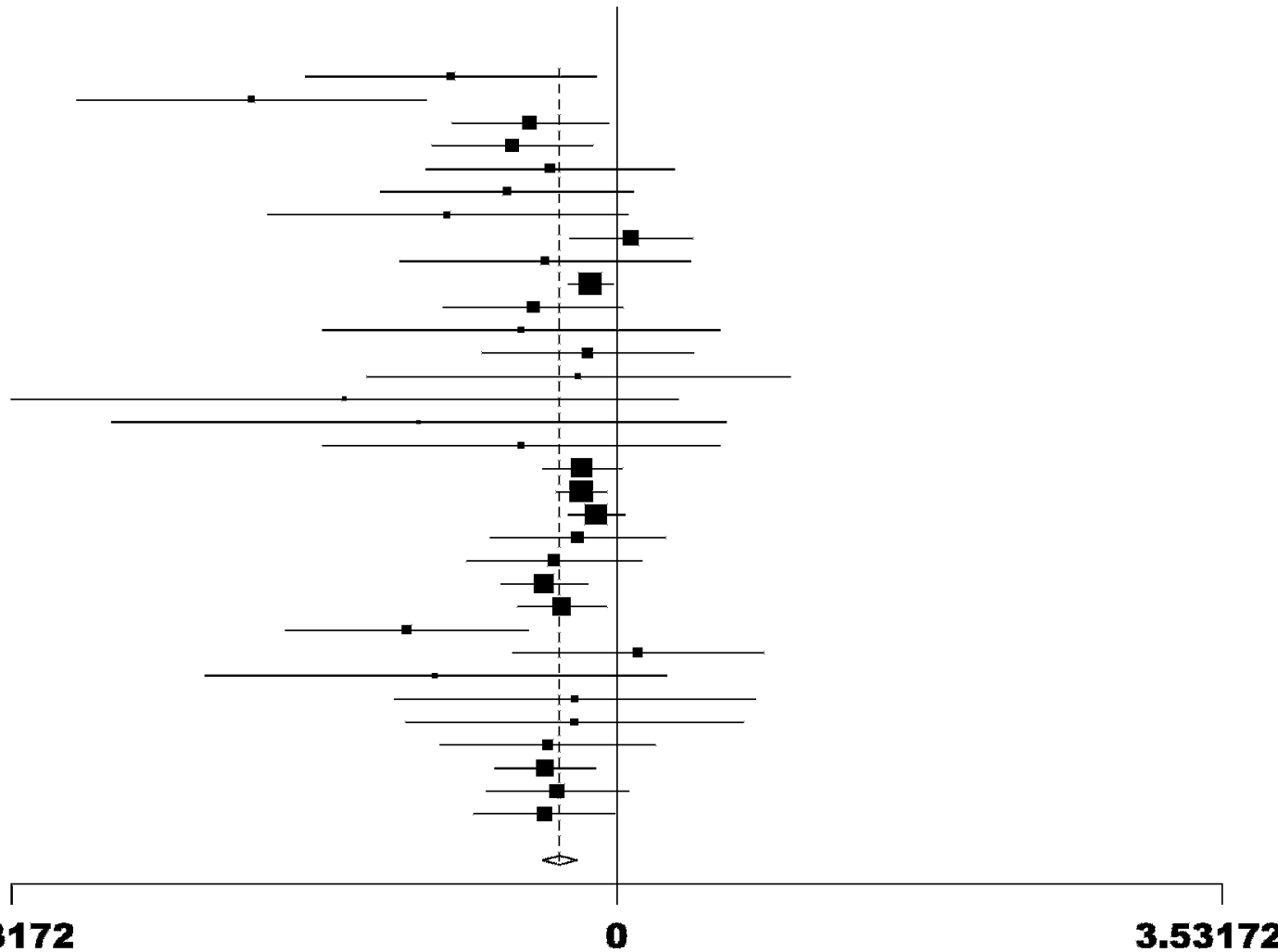

Standardized mean diff.

Figure 1. Forest plot of the effect of monensin on circulating BHBA in lactating dairy cows. Standardized mean diff. $=$ standardized mean difference (standardized using the z-statistic). Thus, points to the left of the line represent a reduction in the trait, whereas points to the right of the line indicate an increase in the variable. Each square represents the mean effect size for that study. The upper and lower limit of the line connected to the square represents the upper and lower 95\% confidence interval (CI) for the effect size. The size of the square reflects the relative weighting of the study to the overall effect size estimate with larger squares representing greater weight. The dotted vertical line represents the overall effect size estimate. The diamond at the bottom represents the 95\% CI for the overall estimate. The solid vertical line represents a mean difference of zero or no effect. Study refers to the first author and year of the publication.

Table 3. Summary of significant meta-regression variables influencing the effect size of monensin on BHBA, glucose, and NEFA in lactating dairy cattle

\begin{tabular}{|c|c|c|c|}
\hline Variable & Coefficient & $\begin{array}{c}95 \% \\
\text { Confidence } \\
\text { interval }\end{array}$ & $P$-value \\
\hline \multicolumn{4}{|l|}{ BHBA } \\
\hline $\mathrm{CRC}^{1}$ or top dress (compared with TMR inclusion as referent) & 0.353 & $(0.272,-0.030)$ & 0.004 \\
\hline Early lactation (<30 DIM) (compared with data from other stages of lactation as referent) & -0.151 & $(0.386,-0.003)$ & 0.012 \\
\hline Pasture-based feeding (compared with other feeding systems as referent) & -0.194 & $(0.113,0.594)$ & 0.050 \\
\hline Precalving period (compared with other stages of lactation as referent) & -0.237 & $(0.385,-0.088)$ & 0.002 \\
\hline $\begin{array}{l}\text { Single control for multiple treatment doses (compared with studies having one treatment } \\
\text { and one control group) }\end{array}$ & 0.250 & $(0.074,0.426)$ & 0.005 \\
\hline Dose $(\mathrm{mg} / \mathrm{d})$ & 0.003 & $(0.0003,0.006)$ & 0.032 \\
\hline Top dress delivery (compared with $\mathrm{CRC}^{1}$ or TMR delivery as referrent) & 0.296 & $(0.055,0.536)$ & 0.016 \\
\hline \multicolumn{4}{|l|}{ NEFA } \\
\hline Intercept & 0.0432 & $(0.167,0.256)$ & 0.691 \\
\hline
\end{tabular}

${ }^{1} \mathrm{CRC}=$ monensin delivered in a controlled-release capsule. 


\section{Begg's funnel plot with pseudo $95 \%$ confidence limits}

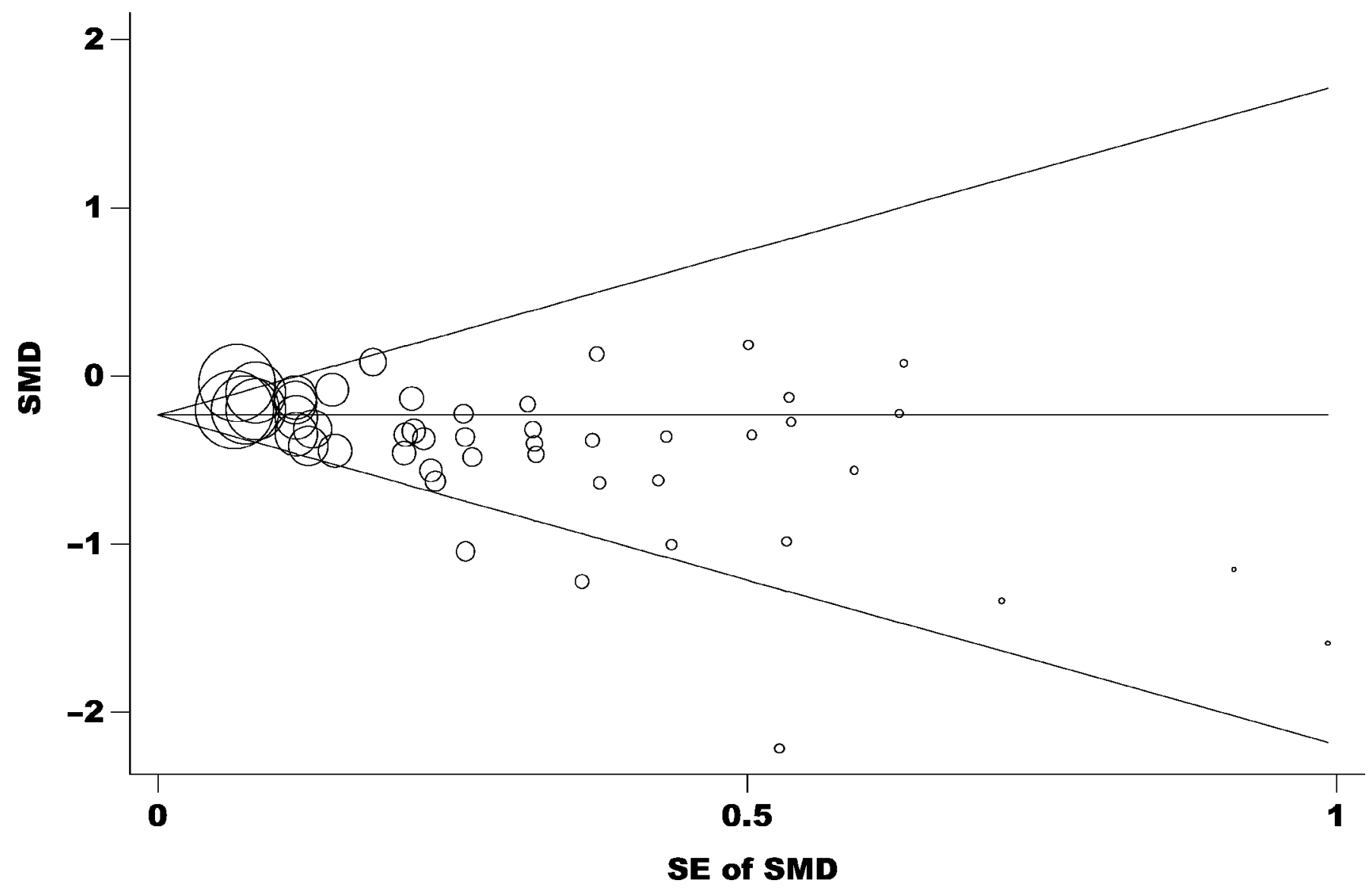

Figure 2. Funnel plot of monensin effect on BHBA for assessing publication bias. SMD = standardized mean difference; SE of SMD = $\mathrm{SE}$ of the standardized mean difference. The relative size of the circles represents the relative weighting of the study with the larger circles representing greater weight. The horizontal line represents the overall effect size estimate. The 2 diagonal lines indicate an estimate of the $95 \%$ confidence interval of the effect size estimate. Interpretation: Publication bias may be present if there are an unequal number of studies (particularly smaller weight studies) on one side of the horizontal line.

by Sauer et al. (1989) resulted in a lower ES for monensin on BHBA, whereas removal of the study by Duffield et al. (1998) caused a higher ES estimate for monensin on BHBA. The removal of these studies did not change the direction or significance of the point estimates.

Effect size estimates for NEFA, glucose, urea, and BHBA from the meta-analyses were cross-tabulated to test pairwise correlations of effect for each of these analytes across studies. The BHBA effect size was the only positively correlated variable with the effect size estimate for NEFA $(\mathrm{r}=0.446 ; P=0.02)$.

\section{DISCUSSION}

The impact of monensin on reducing BHBA was not surprising and was most likely explained by an increased supply of propionate to the liver in treated cattle. Yet, the presence of significant heterogeneity in response was unexpected. Based on the meta-regression analysis, this was largely explained by differences in delivery of monensin. Theoretically, delivery is more consistent, albeit slightly reduced in effect, with delivery in top dress form or in CRC compared with TMR. Stratifying on this factor (consistent delivery) eliminated the heterogeneity for the consistent group (data not presented). For the in-feed group there was 1 outlier (30 ppm treatment in the Sauer et al., 1989); however, significant heterogeneity existed upon removal of this trial from the stratified analysis. This identified variation in effect size seems most likely explained by variations in DMI and, hence, variations in a consistent dose delivered to the cow. Implications of this to the field are that there may be variation in response in ketone concentrations with monensin treatment depending on consistency of delivery of the dose. 


\section{Study}

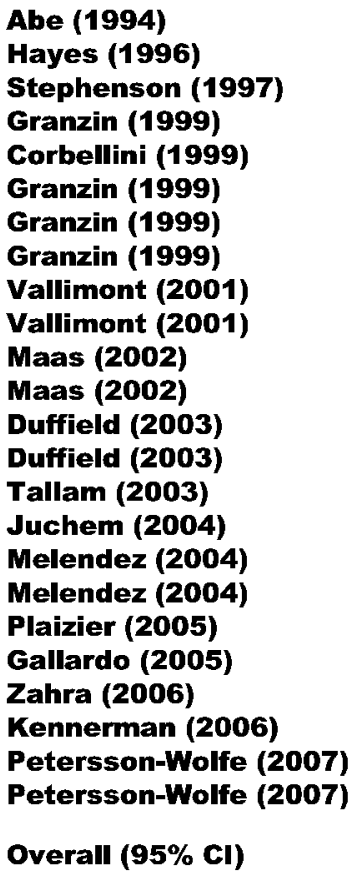

Overall (95\% CI)

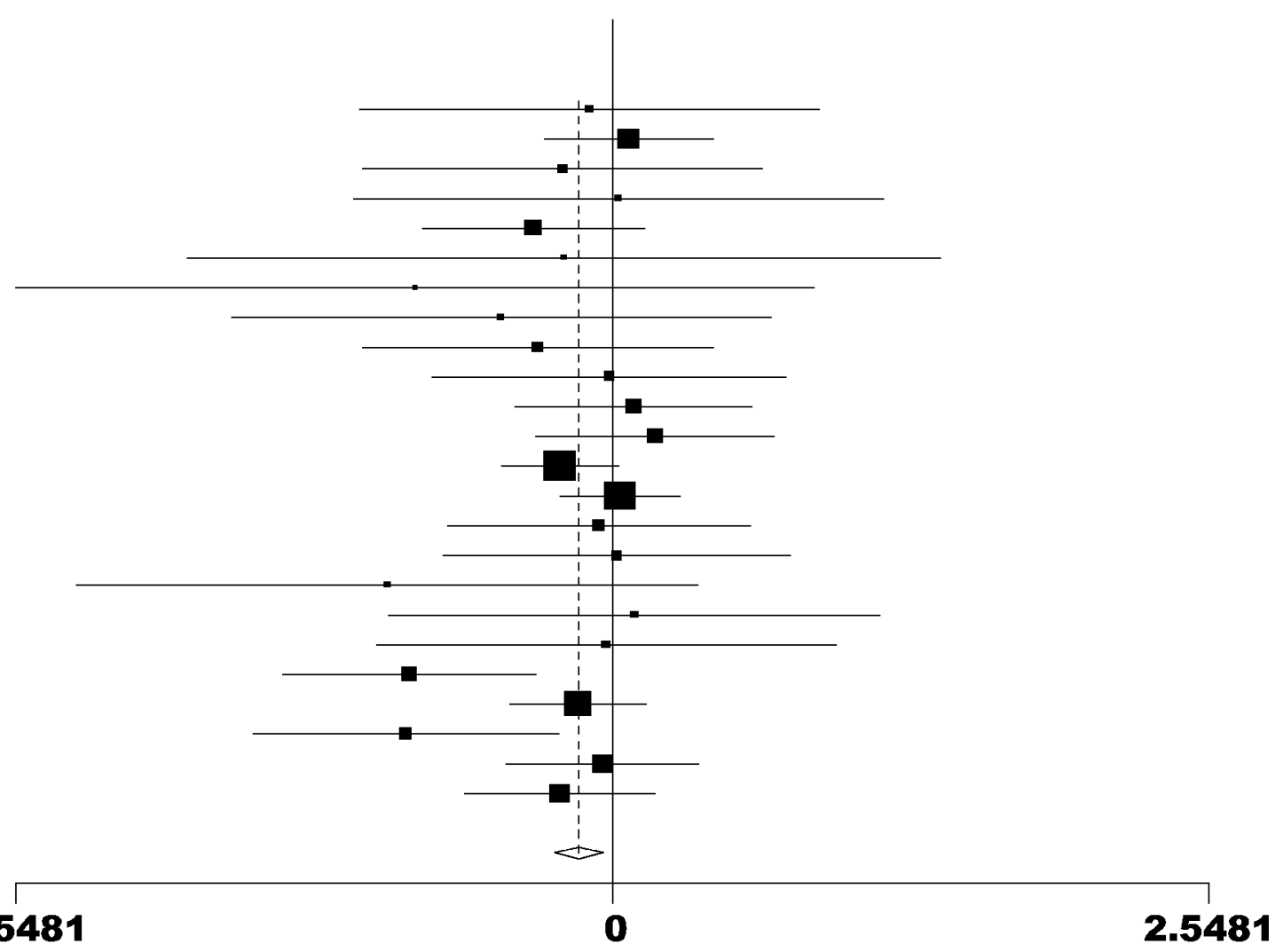

Standardized mean diff.

Figure 3. Forest plot of the effect of monensin on circulating NEFA in lactating dairy cows. Standardized mean diff. $=$ standardized mean difference (standardized using the z-statistic). Thus, points to the left of the line represent a reduction in the trait, whereas points to the right of the line indicate an increase in the variable. Each square represents the mean effect size for that study. The upper and lower limit of the line connected to the square represents the upper and lower 95\% confidence interval (CI) for the effect size. The size of the square reflects the relative weighting of the study to the overall effect size estimate with larger squares representing greater weight. The dotted vertical line represents the overall effect size estimate. The diamond at the bottom represents the $95 \%$ CI for the overall estimate. The solid vertical line represents a mean difference of zero or no effect. Study refers to the first author and year of the publication.

The significance of the early lactation phase in metaregression was expected given previous studies demonstrating stage of lactation interactions with monensin treatment (Abe et al., 1994; Duffield et al., 1998; Petersson-Wolfe et al., 2007). It is probable that cows in early lactation have greater nutrient deficits compared with cows later in lactation; hence, there is a greater positive effect on lowering ketone concentrations for cows in early lactation with monensin treatment. Pasture-based herds had a larger effect size for ketones, which may reflect a greater potential for these herds to be underfed and respond more favorably to increased energy supply.

The publication bias identified in the BHBA analysis was an important observation. The missing data, fortunately, had little impact on the overall effect size estimates, because smaller, lower weight studies were less likely to be published if there was a positive effect, that is, if monensin increased BHBA concentrations. It is possible that given early reports that monensin treatment reduced BHBA concentrations and that this finding was found repeatedly, there may be a bias toward expecting this result. Finding a result contrary to that expected may have led to these studies not being published, especially if the study was conducted on small numbers of cattle. It should be noted that the authors attempted to collect unpublished data. This recognized method is used to reduce the impact of publication bias in meta-analysis (Dohoo et al., 2003c). Use of non-peerreviewed material might be a source of bias because these data are often difficult to find and frequently identified through personal contacts. This problem was addressed in 2 ways. First, all non-peer-reviewed material was subjected to the same screening requirement for randomization, having a control group, and reporting of a measure of dispersion as were the peer-reviewed 


\section{Study}

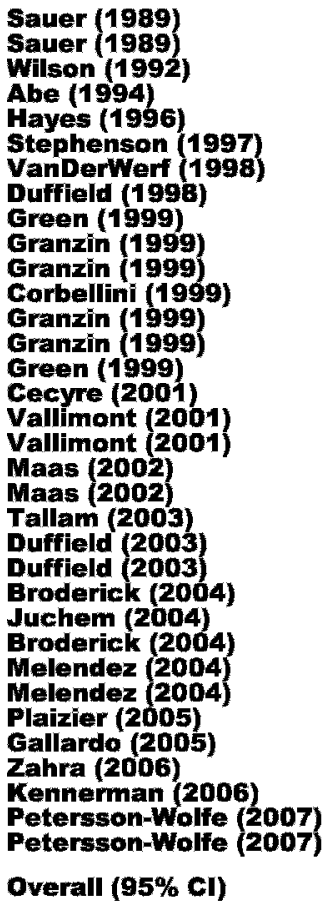

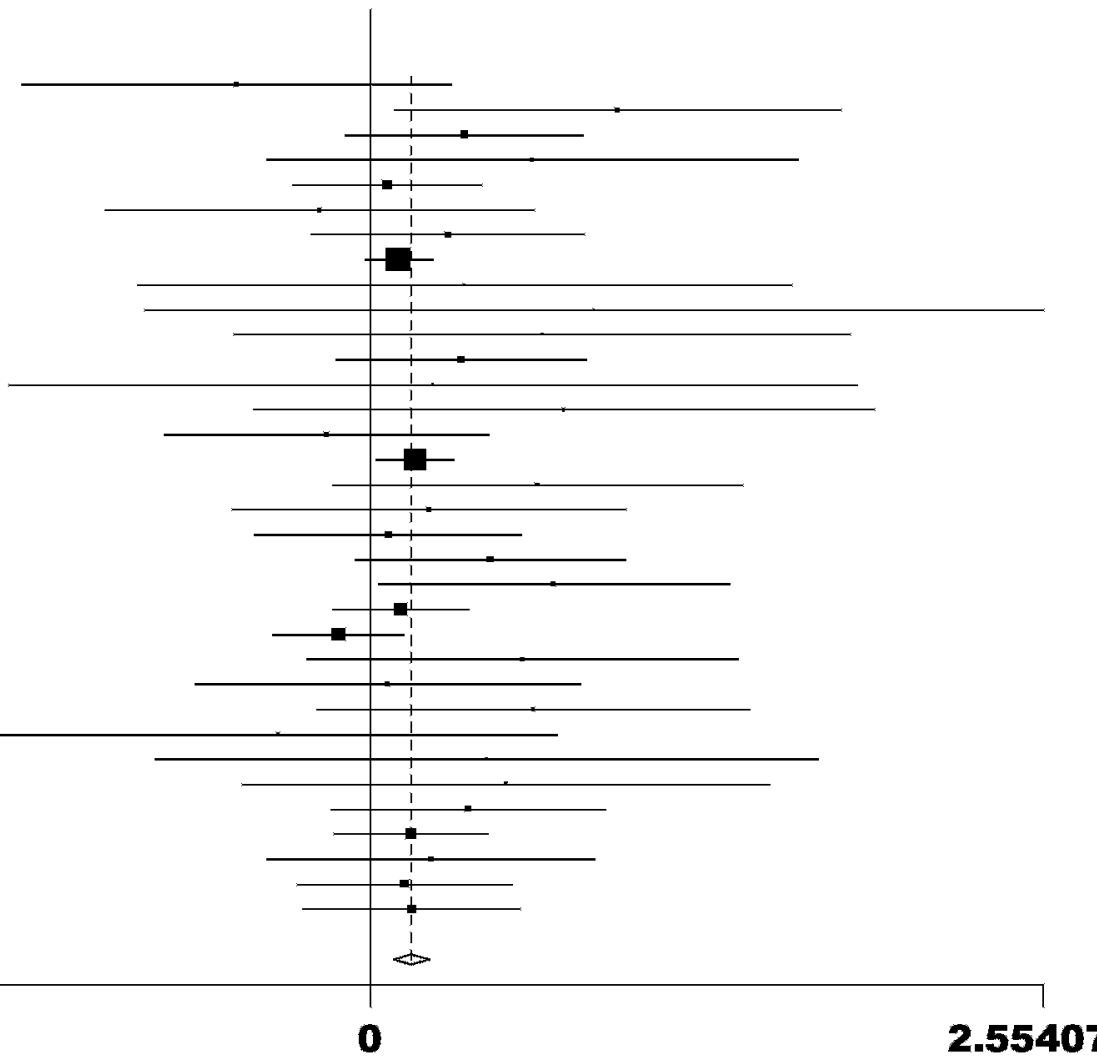

Standardized mean diff.

Figure 4. Forest plot of the effect of monensin on circulating glucose concentrations in lactating dairy cows. Standardized mean diff. $=$ standardized mean difference (standardized using the z-statistic). Thus, points to the left of the line represent a reduction in the trait, whereas points to the right of the line indicate an increase in the variable. Each square represents the mean effect size for that study. The upper and lower limit of the line connected to the square represents the upper and lower 95\% confidence interval (CI) for the effect size. The size of the square reflects the relative weighting of the study to the overall effect size estimate with larger squares representing greater weight. The dotted vertical line represents the overall effect size estimate. The diamond at the bottom represents the $95 \% \mathrm{CI}$ for the overall estimate. The solid vertical line represents a mean difference of zero or no effect. Study refers to the first author and year of the publication.

papers. Second, a dichotomous variable representing data source, peer-reviewed (1) or non-peer-reviewed (0), was created and tested for influence on effect size estimates in all meta-regression. There were no ES estimates that were influenced by data source.

The finding of publication bias for BHBA contrasted with the analysis of all other metabolites, which did not show a publication bias (data not shown). Other metabolite responses with monensin treatment, particularly glucose, NEFA, and cholesterol, in individual studies were frequently not significant, possibly due to the large number of cattle needed to show a statistically significant effect. Consequently, no tendency for a publication bias appeared based on an anticipated response in either direction. Investigators are encouraged to publish positive and negative results of future studies, given the value of pooling studies to provide better estimates of effect and to allow evaluation of sources of heterogeneity.
The finding that glucose concentrations were increased with monensin has not been consistently reported in the literature. The lack of a previously identified response most likely is a function of the response being small and generally requiring a larger sample size to effectively assess the glucose response. Although the effect is small, the response was consistent across studies with no significant heterogeneity. The metaregression findings for glucose were consistent with some of the same factors found significant in the metaregression of BHBA data. One difference between the glucose and BHBA analysis was that the top dress and CRC delivery methods (compared with TMR delivery) both produced slightly reduced responses in the BHBA analysis and were combined into one effect (consistent delivery). Still, these 2 delivery methods provided opposite effects with monensin on glucose, and only the top dress method of delivery remained in the glucose model. The CRC delivered a constant amount over the course 


\section{Study}

Hayes (1996)

Stephenson (1997)

Duffield (1998)

Green (1999)

Green (1999)

Ruîz (2001)

Cecyre (2001)

VanderMerwe (2001)

Vallimont (2001)

Vallimont (2001)

Maas (2002)

Maas (2002)

Tallam (2003)

Duffield (2003)

Duffield (2003)

Broderick (2004)

Broderick (2004)

Plaizier (2005)

Gallardo (2005)

Mohebbi-Fani (2005)

Zahra (2006)

Petersson-Wolfe (2007)

Petersson-Wolfe (2007)

Overall (95\% cl)

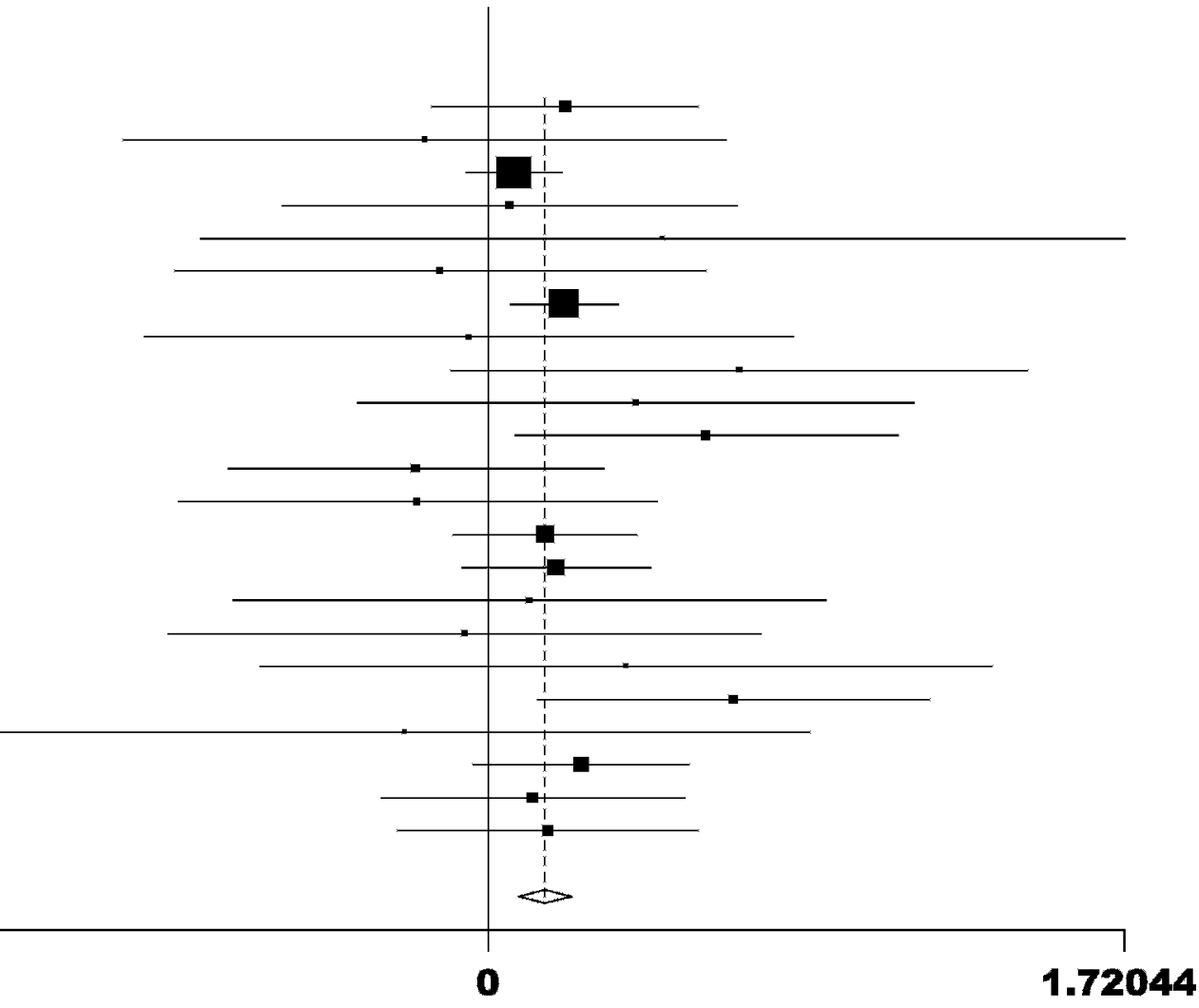

Standardized mean diff.

Figure 5. Forest plot of the effect of monensin on serum or blood urea concentrations in lactating dairy cows. Standardized mean diff. $=$ standardized mean difference (standardized using the z-statistic). Thus, points to the left of the line represent a reduction in the trait, whereas points to the right of the line indicate an increase in the variable. Each square represents the mean effect size for that study. The upper and lower limit of the line connected to the square represents the upper and lower 95\% confidence interval (CI) for the effect size. The size of the square reflects the relative weighting of the study to the overall effect size estimate with larger squares representing greater weight. The dotted vertical line represents the overall effect size estimate. The diamond at the bottom represents the $95 \%$ CI for the overall estimate. The solid vertical line represents a mean difference of zero or no effect. Study refers to the first author and year of the publication.

of the day, and this potentially yielded lower propionate concentrations than spikes of monensin delivered to the rumen once or twice daily. Perhaps the "slug" delivery of monensin created a sudden subsequent increase in rumen propionate that elevated glucose concentrations or was associated with a delivery of a large dose of starch that could stimulate propionate production. Dose of monensin entered this model indicated that with increased milligrams per day of monensin, there is a slight increase in glucose concentrations. This would most likely be a function of a dose:rumen propionate relationship, and this effect was described (Richardson et al., 1976). The finding that samples taken in the precalving period had significantly lower glucose with monensin treatment supports the original suggestion by Stephenson et al. (1997) that the precalving glucose generated by monensin was most likely going to the fetus.
The final variable in the glucose model was the use of the same control group for multiple treatments. This finding has no field application, but highlights that the control group is crucial and regression to the mean or underestimating the standard error without accounting properly for multiple comparisons may unduly influence results in some cases (Dohoo et al., 2003c).

The impact of monensin on serum NEFA concentrations was less extensively studied than BHBA or glucose, and there have been inconsistent responses. But, the meta-analysis clearly showed an effect of monensin on reducing concentrations of NEFA. The only variable significant in meta-regression was inclusion of monensin in the pre- and postcalving diets. This makes biological sense because the highest NEFA concentrations in lactating cows occur a few days before calving to the second week after calving. Treatment should cover the calving period to have maximum effect. 


\section{Meta-analysis estimates, given named study is omitted | Lower Cl Limit | OEstimate $\quad$ Upper Cl Limit}

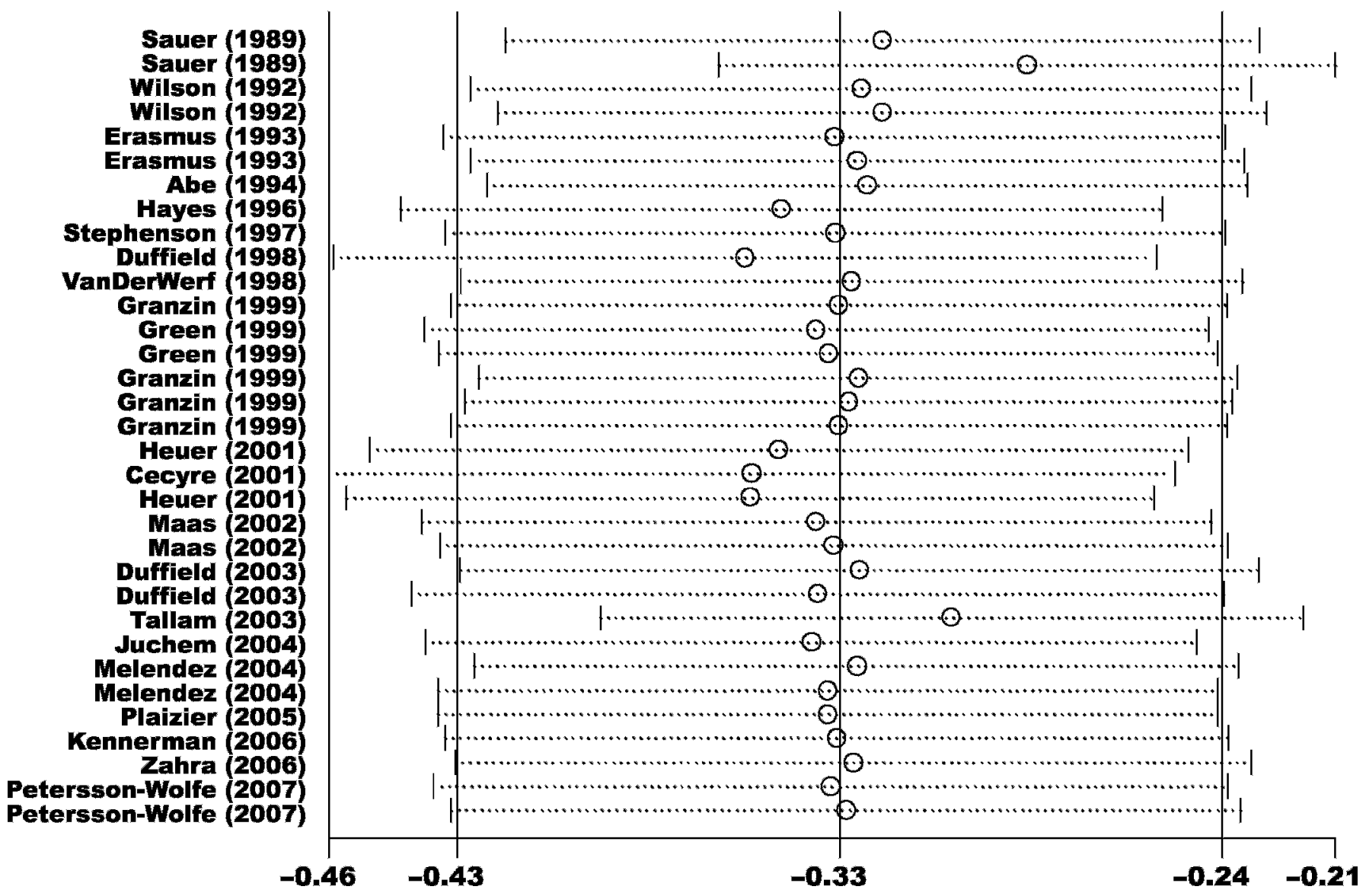

Figure 6. Influence analysis for the effect on monensin on circulating BHBA concentrations. Plot depicts the impact of removing each individual study on the point estimate of the effect size for monensin on circulating BHBA concentrations and on the lower and upper 95\% confidence interval (CI) for the effect size. Numbers at the bottom of the graph refer to the standardized mean difference. Individual studies are listed by first author and year of publication.

A number of individual dairy (Hayes et al., 1996; Duffield et al., 1998; Plaizier et al., 2005) studies reported urea concentrations in blood, plasma, or serum increasing with monensin treatment. We hypothesize that this effect reflected increased protein flux of undegraded protein from the rumen to the small intestine because paradoxically monensin decreased rumen ammonia concentrations by selective inhibition of bacteria that deaminate proteins (Schelling, 1984). The increase in urea concentrations with monensin treatment appeared uncoupled from effects on energy metabolism because of the lack of correlation with glucose, NEFA, or BHBA responses. Some studies suggested that an increased supply of amino acids might lead to increased deamination and increased urea concentrations (Duffield et al., 1998; Plaizier et al., 2005). There is some apparent discrepancy between the ES estimates for mo- nensin on serum and milk urea. Nevertheless, the milk urea data set was relatively small, containing only 69 cows in each treatment group and only 6 trials. In this analysis, 4 of 6 trials had a positive ES for monensin and one trial (van der Merwe et al., 2001) strongly weights the overall ES estimate to the negative side. It is possible that there were methodological differences that explain this finding, although in the current study blood and milk results appeared correlated.

Correlations of the monensin effect size estimates for BHBA and NEFA can assist in understanding metabolism. It appears likely that the increased supply of ruminal propionate with monensin use (Richardson et al., 1976) led to reductions in mobilized body fat (NEFA) and most likely reduced supply of fat to the liver. The BHBA and NEFA effects were correlated $(\mathrm{r}=0.45)$, implying that as monensin decreased NEFA flux, there 
was a concurrent decrease in serum BHBA concentrations. The possibility of lower liver fat and the conversion of propionate to glucose provide both an increase in fat oxidation and a reduction in partial fat oxidation leading to a reduced ketone concentration (BHBA and acetoacetate). Less storage of fat in the liver may lead to improved liver function. Part of the explanation for the observed increase in circulating urea with monensin may be an improved ability of the liver to synthesize urea. Strang et al. (1998) reported that ureagenesis rates from hepatocytes cultured in vitro decreased linearly with previous prolonged exposure to triglycerides.

\section{CONCLUSIONS}

Monensin treatment in lactating dairy cattle reduced the blood concentrations of BHBA, acetoacetate, and NEFA. Monensin increased glucose and urea concentrations in blood, plasma, and serum. These findings follow a logical pattern of improved, coordinated energy metabolism, which is particularly beneficial for the transition dairy cow in providing a more positive adaptive response to the challenges of lactation. A consistent delivery of monensin to cattle, timing of administration to start precalving and continue through the early lactation period, and to a small degree, dose of treatment, appear to influence effect size estimates for monensin on these blood analytes.

\section{ACKNOWLEDGMENTS}

We wish to acknowledge Veletta Taylor (Strategic Bovine Services, Camden, New South Wales, Australia) for her assistance with the literature search and Elanco Animal Health (Guelph, Ontario, Canada; Macquarie Park, New South Wales, Australia; Greenfield, IN) for generous funding support for this project.

\section{REFERENCES}

Abe, N., I. J. Lean, A. Rabiee, J. Porter, and C. Graham. 1994. Effects of sodium monensin on reproductive performance of dairy cattle. II. Effects on metabolites in plasma, resumption of ovarian cyclicity and oestrus in lactating cows. Aust. Vet. J. 71:277-282.

Begg, C., and M. Manumdar. 1994. Operating characteristics of a rank correlation test for publication bias. Biometrics 50:1088-1101.

Broderick, G. A. 2004. Effect of low level monensin supplementation on the production of dairy cows fed alfalfa silage. J. Dairy Sci. 87:359-368.

Cécyre, D. 2001. Facteurs de variation et réévaluation des valeurs de référence du profil métabolique chez les bovins laitiers du Québec. MSc dissertation Université de Montréal, St. Hyacinthe, Quebec, Canada.

Corbellini, C. 1999. Experiencias en la Argentina con el uso de aditivos alimentarios en vacas lecheras. Pages $94-108$ in Seminario Internacional CAPACITAGRO: Bioenergética de la lactancia en vacas lecheras Estrategias productivas, nutricionales, reproductivas y de salud animal. Fac. C. Agrarias, Univ. Católica Argentina, Bs. As.
Dohoo, I. R., K. Leslie, L. DesCoteaux, A. Fredeen, P. Dowling, A. Preston, and W. Shewfelt. 2003a. A meta-analysis review of the effects of rBST. 1. Methodology and effects on production and nutrition related parameters. Can. J. Vet. Res. 67:241-251.

Dohoo, I., W. Martin, and H. Stryhn. 2003b. Meta-analysis. Page 706 in Veterinary epidemiologic research AVC Inc., Charlottetown, Prince Edward Island, Canada.

Dohoo, I., W. Martin, and H. Stryhn. 2003c. Veterinary Epidemiologic Research. AVC Inc., Charlottetown, Prince Edward Island, Canada.

Duffield, T. F., S. LeBlanc, R. Bagg, K. Leslie, J. Ten Hag, and P. Dick. 2003. Effect of a monensin controlled release capsule on metabolic parameters in transition dairy cows. J. Dairy Sci. $86: 1171-1176$.

Duffield, T. F., K. E. Leslie, D. Sandals, K. Lissemore, B. W. McBride, J. H. Lumsden, P. Dick, and R. Bagg. 1998. Effect of prepartum administration of monensin in a controlled-release capsule on postpartum energy indicators in lactating dairy cows. J. Dairy Sci. 81:2354-2361.

Egger, M., G. Davey Smith, and D. Altman. 2001. Systematic reviews in health care. Meta-analysis in context. BMJ Books, London, UK.

Egger, M., G. Davey Smith, M. Schneider, and C. Minder. 1997. Bias in meta-analysis detected by a simple, graphical test. BMJ 315:629-634.

Erasmus, L. J., P. M. Botha, G. D. Lindsey, J. A. d'Assonville, and M. D. Viljoen. 1993. Effect of monensin supplementation and BST administration on productivity and incidence of ketosis in dairy cows. Pages 413-414 in World Conference on Animal Production, Edmonton, Canada.

Erasmus, L. J., C. Muya, S. Erasmus, and D. G. Catton. 2006. Effect of Virginiamycin and Poulcox, or both, on performance of Holstein cows. J. Dairy Sci. 89(Suppl. 1):234. (Abstr.)

Gallardo, M. R., A. R. Castillo, F. Bargo, A. A. Abdala, M. G. Maciel, H. Perez Monti, H. C. Castro, and M. E. Castelli. 2005. Monensin for lactating dairy cows grazing mixed-alfalfa pasture and supplemented with partial mixed ration. J. Dairy Sci. 88:644-652.

Granzin, B. C., and G. McL. Dryden. 1999. The effects of monensin on milk production and levels of metabolites in blood and rumen fluid of Holstein-Friesian cows in early lactation. Aust. J. Exp. Agric. 39:933-940.

Green, B. L., B. W. McBride, D. Sandals, K. E. Leslie, R. Bagg, and P. Dick. 1999. The impact of a monensin controlled-release capsule on subclinical ketosis in the transition dairy cow. J. Dairy Sci. 82:333-342.

Haney, M., and M. Hoehn. 1967. Monensin, a new biologically active compound I: Discovery and isolation. Antimicrob. Agents Chemother. 349:349.

Hayes, D. P., D. U. Pfeiffer, and N. B. Williamson. 1996. Effect of intraruminal monensin capsules on reproductive performance and milk production of dairy cows fed pasture. J. Dairy Sci. 79:1000-1008.

Hendrick, S. H., D. F. Kelton, K. E. Leslie, K. D. Lissemore, M. Archambault, R. Bagg, P. Dick, and T. F. Duffield. 2006. Efficacy of monensin sodium for the reduction of fecal shedding of Mycobacterium avium subsp. paratuberculosis in infected dairy cattle. Prev. Vet. Med. 75:206-220.

Heuer, C., Y. H. Schukken, L. J. Jonker, J. I. D. Wilkinson, and J. P. T. M. Noordhuizen. 2001. Effect of monensin on blood ketone bodies, incidence and recurrence of disease and fertility in dairy cows. J. Dairy Sci. 84:1085-1097.

Higgins, J. P. T., S. G. Thompson, J. J. Deeks, and D. G. Altman. 2003. Measuring inconsistency in meta-analyses. BMJ 327:557-560.

Juchem, S. O., F. A. P. Santos, H. Imaizumi, A. V. Pires, and E. C. Barnabe. 2004. Production and blood parameters of Holstein cows treated prepartum with sodium monensin or propylene glycol. J. Dairy Sci. 87:680-689.

Kennerman, E., S. Senturk, and H. Biricik. 2006. Effect of monensin controlled release capsules on blood metabolites in periparturient dairy cows. Aust. Vet. J. 84:282-284.

Lean, I. J., P. J. DeGaris, D. M. McNeal, and E. Block. 2006. Hypocalcemia in dairy cows: Meta-analysis and dietary cation anion difference theory revisited. J. Dairy Sci. 89:669-684. 
Maas, J. A., S. N. McCutcheon, G. F. Wilson, G. A. Lynch, M. E. Hunt, and L. A. Crompton. 2002. The effect of monensin sodium on lactational performance of autumn and spring calving cows. J. Dairy Res. 69:317-323.

Melendez, P., J. P. Goff, C. A. Risco, L. F. Archbald, R. Littell, and G. A. Donovan. 2004. Effect of a monensin controlled-release capsule on rumen and blood metabolites in Florida Holstein transition cows. J. Dairy Sci. 87:4182-4189.

Mohebbi-Fani, M., S. Nazifi, S. Shekarforush, and S. Fathi. 2005. Changes of protein fractions, lipoproteins, ceruloplasmin and urea nitrogen in serum of periparturient cows receiving dietary monensin. Rev. Med. Vet. (Toulouse) 156:170-174.

Mohebbi-Fani, M., S. Nazifi, S. Shekarforoush, and M. Rahimi. 2006. Effect of monensin on serum lipoproteins, triglycerides, cholesterol and total lipids of periparturient dairy cows. Vet. Res. Commun. 30:7-17.

Petersson-Wolfe, C. S., K. E. Leslie, T. Osborne, B. W. McBride, R. Bagg, G. Vessie, P. Dick, and T. F. Duffield. 2007. Effect of delivery method of monensin on dry matter intake, body condition score, and metabolic parameters in transition dairy cows. J. Dairy Sci. 90:1870-1879.

Plaizier, J. C., A. M. Fairfield, P. A. Azevedo, A. Nikkhah, T. F. Duffield, G. H. Crow, R. Bagg, P. Dick, and B. W. McBride. 2005. Effects of monensin and stage of lactation on variation of blood metabolites within twenty-four hours in dairy cows. J. Dairy Sci. 88:3595-3602.

Richardson, L., A. Raun, E. Potter, C. Cooley, and R. Rathmacher. 1976. Effect of monensin on rumen fermentation in vitro and in vivo. J. Anim. Sci. 43:657-664.

Rosenthal, R. 1979. The "file drawer problem" and tolerance for null results. Psychol. B. 86:638-641.

Ruiz, R., G. L. Albrecht, L. O. Tedeschi, G. Jarvis, J. B. Russell, and D. G. Fox. 2001. Effect of monensin on the performance and nitrogen utilization of lactating dairy cows consuming fresh forage. J. Dairy Sci. 84:1717-1727.

Sauer, F. D., J. K. G. Kramer, and W. J. Cantwell. 1989. Antiketogenic effects of monensin in early lactation. J. Dairy Sci. 72:436-442.
Schelling, G. 1984. Monensin mode of action in the rumen. J. Anim. Sci. 58:1518-1527.

Stephenson, K. A., I. J. Lean, M. L. Hyde, M. A. Curtis, J. K. Garvin, and L. B. Lowe. 1997. Effects of monensin on the metabolism of periparturient dairy cows. J. Dairy Sci. 80:830-837.

Stephenson, K. A., I. J. Lean, and T. O'Meara. 1996. The effect of monensin on the chemotactic function of bovine neutrophils. Aust. Vet. J. 74:315-317.

Strang, B., S. Bertics, R. Grummer, and L. Armentano. 1998. Effect of long-chain fatty acids on triglyceride accumulation, gluconeogenesis, and ureagenesis in bovine hepatocytes. J. Dairy Sci. 81:728-739.

Tallam, S. K., T. F. Duffield, K. E. Leslie, R. Bagg, P. Dick, G. Vessie, and J. S. Walton. 2003. Ovarian follicular activity in lactating Holstein cows supplemented with monensin. J. Dairy Sci. 86:3498-3507.

Vallimont, J. E., G. A. Varga, A. Arieli, T. W. Cassidy, and K. A. Cummins. 2001. Effects of prepartum somatotropin and monensin on metabolism and production of periparturient Holstein dairy cows. J. Dairy Sci. 84:2607-2621.

van der Merwe, B. J., T. J. Dugmore, and K. P. Walsh. 2001. The effect of monensin on milk production, milk urea nitrogen and body condition score of grazing dairy cows. S. Afr. J. Anim. Sci. 31:49-55.

Van der Werf, J. H. J., L. J. Jonker, and J. K. Oldenbroek. 1998. Effect of monensin on milk production by Holstein and Jersey cows. J. Dairy Sci. 81:427-433.

Wilson, G. F., G. A. Lynch, and C. van der Wel. 1992. Effects of Rumensin anti-bloat capsules on plasma magnesium concentration and aspects of health and performance of pastured dairy cows. Trial Report. Massey University, Department of Animal Health, Palmerston North, New Zealand.

Zahra, L. C., T. F. Duffield, K. E. Leslie, T. R. Overton, D. Putnam, and S. J. LeBlanc. 2006. Effects of rumen-protected choline and monensin on milk production and metabolism of periparturient dairy cows. J. Dairy Sci. 89:4808-4818. 